\title{
El rol de la institucionalidad pública en experiencias autogestionarias de vivienda en Argentina
}

\section{The role of public institutions in experiences of self-management housing in Argentina}

\author{
Ma. Cecilia Zapata*
}

\begin{abstract}
This paper examines the way of implementing the Self-management Housing Program (Programa de Autogestion de la Vivienda, PAV) in the city of Buenos Aires (Argentina) by various managements of government that were in charge of its implementation since 2000 - the year of its creation - to the present day and its impact on the experiences of self-management of popular ongoing habitat. Even with its limitations (external) ${ }^{1}$ and constraints (internal) ${ }^{2}$, the social and collective experiences associated with the design and implementation of PAV contributed to the construction of a significant field of dispute for the democratization of city production and appropriation of urban centrality, claiming for the sectors with low incomes the right to the city and habitat.
\end{abstract}

Keywords: Self-management of housing, State, social production of habitat, social participation.

\section{Resumen}

En este artículo se analiza el Programa de Autogestión para la Vivienda (PAV) en la ciudad de Buenos Aires (Argentina) a través de las distintas gestiones de gobierno que estuvieron a cargo de su implementación y ejecución desde el 2000 -año de su creación- hasta la actualidad y su impacto en las experiencias de autogestión del hábitat popular en curso. Aún con limitantes (externos) ${ }^{3}$ y limitaciones (internas), ${ }^{4}$ las experiencias sociales y colectivas asociadas al diseño e implementación del PAV contribuyeron a la construcción de un significativo campo de disputa por la democratización de la producción de ciudad y la apropiación de la centralidad urbana, reivindicando para los sectores de menores recursos el derecho a la ciudad y al hábitat.

Palabras claves: Autogestión de vivienda, Estado, producción social del hábitat, participación social.

${ }^{1}$ Primarily promoted by the State action (as discussed below).

${ }^{2}$ Own social organizations and their ability to sustain over time-for extension of time to implement the program, self-management processes.

${ }^{3}$ Fundamentalmente promovidos por el accionar estatal (como se verá más adelante).

${ }^{4}$ Propias de las organizaciones sociales y su capacidad de sostener en el tiempo -por la extensión del lapso de implementación del programa- los procesos de autogestión.

* Universidad de Buenos Aires y el Consejo Nacional de Investigaciones Científicas y Técnicas (Conicet). correo-e: ceciliazapata@gmail.com 


\section{Introducción}

Esta investigación analiza la implementación y el funcionamiento del Programa de Autogestión para la Vivienda (PAV) en la Ciudad Autónoma de Buenos Aires (CABA), el cual surge en el 2000 -año de sanción de la Ley 341-y es ejecutado por el Instituto de la Vivienda de la Ciudad (IVC); a partir de las diversas gestiones de gobierno ${ }^{5}$ este programa ha experimentado diferentes cambios de acuerdo con las distintas posturas políticas e ideológicas, lo cual le ha dado un tinte particular. Por lo que este artículo pretende detectar los puntos de tensión del proceso de producción autogestionaria del hábitat popular a nivel local ${ }^{6}$ en sus distintas gestiones de gobierno, a fin de rastrear los factores tanto estructurales como sectoriales que impactaron en su desarrollo a lo largo de los años (el análisis se realiza hasta diciembre de 2013).

No obstante los vaivenes que sufrió el programa en su proceso de implementación, el PAV presentó rasgos novedosos y superadores con respecto a los programas promotores de vivienda social vigentes en $\mathrm{Ar}$ gentina (y en América Latina). Las experiencias sociales y colectivas, asociadas al diseño e implementación del programa en cada una de sus operatorias desarrolladas, contribuyeron a la construcción de un significativo campo de disputa en la ciudad, debido a la democratización de la producción del hábitat popular y la apropiación de la centralidad urbana por parte de los sectores de escasos recursos, en un ejercicio explícito del derecho que estos sectores tienen a la ciudad.

El programa fue concebido y diseñado por organizaciones sociales de base que luchaban a principios del siglo a nivel local por el derecho a la vivienda y a la ciudad, ${ }^{7}$ nutriéndose de experiencias del resto de América Latina. ${ }^{8}$ El pav logró un desarrollo marginal en relación a la política ha-

\footnotetext{
${ }^{5}$ Presidencias de la CMV-IVC: Eduardo Jozami, 2000-2002; Ernesto Selzer (jefatura de Aníbal Ibarra), 2002-2006; Claudio Freidín (jefatura de Jorge Telerman), 2006-2007; Roberto Apelbaum, 2007-2010; Omar Abboud, 2010-2011; y Emilio Basavilbaso (jefatura de Mauricio Macri) de 2011 hasta la actualidad.

${ }^{6}$ Vale aclarar que a nivel de la CABA, las experiencias de autogestión que se encuadran en este programa son las únicas que encontraron asidero en la ciudad en la última década.

${ }^{7}$ En los últimos ańos de la década de los noventa, en la Legislatura de la CABA se conformó una mesa de trabajo que capitalizó las distintas experiencias vinculadas al hábitat en la ciudad y que contó con la participación de una gran cantidad de organizaciones sociales. El resultado de esta articulación fue la sanción de la Ley 341, normada en febrero del 2000, que tuvo la característica de haber sido aprobada con el apoyo de todos los bloques de la Legislatura. La organización, la discusión y la movilización consiguieron que un reclamo, que siempre fue genuino, fuera escuchado y tomado en cuenta. Consecuentemente, la ley nació de un proceso de lucha de organizaciones sociales que buscaban una solución a la grave situación habitacional de la CABA, e implicó un reconocimiento explícito por parte del Estado de las formas de organización de los sectores populares y la legitimación de la autogestión. Para más detalles, ver Zapata (2013), capítulo V.

${ }^{8}$ En México, entre 1976 y 1982, la cooperativa "Palo Alto" se convirtió en referente para el diseño de varios instrumentos de política pública y programas como el Fondo Nacional de Habitaciones Populares (Fonhapo), aún vigente, aplicado en la reconstrucción de la ciudad central a raíz
} 
bitacional ejecutada de corte claramente neoliberal y con fines de obtención de ganancia por sobre su posibilidad de uso. Pero en un contexto de políticas urbanas y habitacionales orientadas a la construcción de ciudades globales (Sassen, 1997 y 2002), el abordaje de estas experiencias autogestionarias constituye en una importante contribución teórica y empírica en materia urbana, en términos académicos, como instrumento de política social orientadas desde una perspectiva de derecho.

El objetivo de este artículo es indagar, entonces, en las características que asumió el PAV en su proceso de ejecución a través de distintas gestiones de gobierno, poniendo énfasis en las operatorias que actualmente se encuentran finalizadas y en curso, asimismo se pretende identificar los factores que estimularon y desalentaron los procesos de producción social del hábitat que este programa promueve, identificándolos como puntos de tensión.

Para ello, primeramente, se recurrió a una reconstrucción cuantitativa de los avances del programa año por año en términos de organizaciones sociales inscritas, terrenos adquiridos en la CABA, obras iniciadas y finalizadas. Este abordaje cuantitativo fue posible debido al acceso a la base de datos de avances de obras brindado por la Unidad de Gestión del PAV del IVC.

Posterioremente, se realizó un análisis cualitativo del desarrollo del PAV, prestando especial atención en las distintas gestiones de gobierno que estuvieron a cargo de su implementación, para rastrear la incidencia en la ejecución del programa. Para lo cual se entrevistó a actuales y antiguos funcionarios públicos vinculados al PAV y se realizaron observaciones participantes en reuniones entre éstos y organizaciones sociales adjudicatarias que fueron documentadas en notas de campo. Lo que se busca recabar en estas reuniones eran datos que permitan re-construir el carácter de la relación existente entre ambos factores. De tal modo que el análisis cruzado de la información primaria y secundaria permitió reconstruir y analizar el desarrollo del programa a lo largo del tiempo.

\section{Las políticas habitacionales desde una perspectiva de derecho}

Iniciada la decada de los setenta, pero con mayor fuerza desde mediados de los noventa, en el continente y, específicamente en Argentina, se pro-

de los sismos de 1985. Por su parte en Uruguay, a partir de cuatro experiencias piloto se sancionó una ley nacional de vivienda que desarrolló un sistema de financiación a las cooperativas de alcance nacional, privilegiando la producción autogestionaria, que en los años setenta posibilitó la emergencia de la Federación Uruguaya de Coperativas de Vivienda por Ayuda Mutua (fUCVAM). A partir de los noventa, esta experiencia fue retomada en el desarrollo de otras, como los programas de mutirones de San Pablo, las cooperativas de autogestión en la ciudad de Buenos Aires (que se enmarcaron en la Ley 341/00) y otras que se replican actualmente en Bolivia, Paraguay, Perú, Venezuela y Centroamérica. 
dujeron aceleradas y profundas transformaciones espaciales, sociales y culturales que dieron cuenta de un nuevo tipo de organización territorial del poder económico, caracterizado por mercados abiertos y desregulados de la acción estatal que abonaron a una generalizada liberalización económica y mercantilización del modo de vida. No obstante, estas transformaciones también se explican, de cierto modo, a partir de un cambio en la presencia, injerencia y responsabilidades del Estado (Brenner y Theodore, 2002; Harvey, 2007).

A medida que se generaron procesos de destrucción, desarticulación, deslegitimación de artefactos y políticas e instituciones del estado de bienestar se impulsó la construcción y consolidación de nuevas institucionalidades estatales implementadas para facilitar dinámicas estrictamente mercantilizadoras de la producción de la ciudad (De Mattos, 2002). Por ende, este fenómeno estuvo acompañado de un cambio en el modo de gestión urbana, basado en una disminución significativa de la intervención e inversión público-estatal que instaló al capital privado en el centro del desarrollo urbano.

En lo estrictamente sectorial, las intervenciones orientadas al acceso a la vivienda no fueron la excepción, y modelaron las formas de residencia de las personas. Según Oszlak (1991) las políticas habitacionales representan un cúmulo de acciones u omisiones que expresan la intervención estatal en relación a la distribución/localización de los diversos grupos sociales en la ciudad y las consecuentes posibilidades de satisfacción diferencial de ciertas necesidades básicas que se asocian a dicha ubicación (en términos de posibilidad de acceso a infraestructura de salud, educación, ocio, calidad de vida, etcétera).

En este sentido, la intervención estatal de los últimos años demostró límites para dar respuesta al déficit habitacional de los sectores de menores recursos, a partir de la oferta de programas mercantilizadores de la política social. ${ }^{9}$ Ante esta insuficiencia, surgieron no sólo en Argentina sino en el resto de América Latina, procesos de autoproducción de la vivienda y de la ciudad, desligados de una búsqueda estricta de ganancia y desplegados por los sectores que no lograron el acceso, vía el mercado o la política pública. Estas estrategias populares se caracterizaron por ser heterogéneas, algunas de ellas en abierta contradicción con la lógica capitalista, o bien, insertas de manera indirecta en ella.

Apaolaza (2009), con base en estas particularidades, propone que las experiencias de hábitat popular son construidas de forma capitalistas-no capitalistas, refiriendo a las maneras en que se construyen las unidades

\footnotetext{
${ }^{9}$ Es decir de programas que exigían cierto nivel de bancarización y por ende de demostración de ingreso, ahorro previos, entre otros requisitos de acceso. Algunos de ellos, ejecutados en Argentina en los últimos ańos son Vivienda Porteńa, Mi Primera Casa, Casa BA.
} 
físicas o la infraestructura básica (ya sean calles, veredas, espacios verdes, etc.); en un marco de legalidad-ilegalidad, esto porque la mayoría de los hábitat populares posee niveles de irregularidad en algunos o todos sus aspectos constitutivos: tenencia de la tierra o vivienda, provisión de servicios, entre otros; localización central-periférica, depende directamente de la renta urbana y, por ende, precio de los terrenos y las propiedades, disponibilidad de servicios (entre los más importantes, el transporte público), infraestructura, etcétera; finalmente, el hábitat popular es resultado de la acción individual-grupal, como producto de la acción individual o, por el contrario, como resultado de acciones colectivas.

Esta última característica es central para esta investigación, pues considero que el tipo de participación en el proceso de producción del hábitat popular opera como una variable superlativa sobre el grado de espontaneidad o planificación de la acción colectiva y, además, sobre la presencia o no de una visión integral sobre la problemática habitacional que los conjunta.

En este sentido, retomando a Rodríguez (2007), el concepto de producción social del hábitat ( $\mathrm{PSH})^{10}$ define un determinado conjunto dentro de la variedad de modalidades de producción del hábitat generadas históricamente por los sectores de menores ingresos. La PSH comprende una diversidad de procesos que van desde la materialización de barrios originados en tomas de tierras o villas, hasta la producción de conjuntos cooperativos autogestionarios, desde la autoconstrucción familiar hasta la autogestión colectiva y organizada; pero segun Rodríguez (2007: 27) tienen como base común:

...haber sido concebidas de manera planificada y son dirigidas y controladas por sus productores/originadores (el sujeto es un actor social, distinto de una unidad doméstica centrada en objetivos de su propia reproducción), pudiendo existir diversos tipos de destinatarios individuales-familiares o colectivos-organizados. La práctica de dirección y control del proceso productivo se plasma -con variantes-a través de las diversas fases del mismo: diseño, ejecución, distribución y uso.

Ahora bien, es imperante dejar en claro que no todas las modalidades de autoproducción implementadas históricamente por los sectores de menores ingresos se comprenden en el concepto de PSH, sino sólo aquellas en las que el actor social o sociopolítico que interviene sostiene el control del proceso productivo en todas sus etapas (Rodríguez, 2007). En tal

\footnotetext{
${ }^{10}$ PSH no es un concepto originado en el contexto de la reflexión académica, sino en un particular contexto de interacción multiactoral: la Coalición Internacional para el Hábitat América Latina (HIC-AL), donde confluyen organizaciones no gubernamentales, movimientos y organizaciones sociales de base, activistas de derechos humanos y grupos académicos de diversos países de cada región, en torno al hábitat popular y la defensa de su derecho (Rodríguez, 2007: 14).
} 
sentido, la autoconstrucción, por ejemplo, implica sólo una fase del proceso productivo (la fase de ejecución) y no necesariamente el control del mismo (es la práctica de construir la vivienda o los componentes del hábitat por sus propios usuarios, bajo formas individuales, autoayuda) y, en la mayoría de los casos, encuentra su fundamento en la necesidad individual/familiar. Por ende, la autoconstrucción puede o no articularse en modalidades en PSH en el caso de quien sea el actor que controla el proceso productivo.

Por otra parte, dentro de las variantes de PSH, la autogestión es una forma de producción del hábitat esencialmente colectivo y organizado, en el que las organizaciones sociales mantienen el control del proceso a lo largo de todas las etapas de producción y, necesariamente, desde mi punto de vista, implica la incumbencia de recursos del Estado en el proceso productivo. Ahora bien, esta propuesta autogestionaria para la producción de hábitat se imbrica en un enfoque de integralidad, y parte, en su concepción, del ejercicio del derecho a la vivienda y al hábitat así como a la ciudad, en cuanto a la función social que ésta despliega.

La construcción social que se desenvuelve en paralelo al proceso autogestionario de construcción de vivienda se concibe como expresión del acto de habitar: más que como un objeto como un proceso, más que como un producto un resultado; es decir, representa un ejercicio de práctica real de acceso al derecho a la vivienda y un hábitat adecuado y habilitante al derecho a la ciudad.

El derecho a la vivienda, desde la perspectiva de Borbón (2003), involucra a un conjunto de otros derechos tales como los civiles, económicos, culturales y políticos que contienen aspectos cualitativos de la vivienda, los cuales exceden su tenencia o no en propiedad. Poniendo distancia con aquellas concepciones que interpretan de forma techista al derecho a la vivienda, en donde la misma asume, además, la función de patrimonio y los esfuerzos masivos del Estado y la sociedad se orientan a la producción de nuevos propietarios. El autor enfatiza la función social de la propiedad y de la ciudad en el marco de aspectos relacionados con la calidad de vida que hace a una vivienda digna.

El autor pondera el conjunto vivienda digna por sobre el de la casa en sí mismo (espacio privado):

la vía o el sendero de acceso, la iluminación de la calle, la arborización, las conexiones y la calidad de los servicios de agua potable y alcantarillados de aguas servidas y aguas de lluvia, la energía eléctrica o el gas, los espacios para la recreación y el encuentro como parques y salones comunales, la infraestructura de servicios complementarios como jardines de niños, escuelas y colegios, centros de salud y zonas de comercio y servicios, constituyen partes integrales e inseparables de las viviendas (Borbón, 2003: 24). 
Lefebvre (1968), por su parte, estimula a que entre los derechos básicos de los ciudadanos como libertad, trabajo, salud o educación se incluya el derecho a la ciudad, entendido éste como el derecho de los ciudadanos a vivir en territorios en donde se propicie la convivencia y ricos en usos diversos, en los que el espacio y los equipamientos sociourbanos sean factores del desarrollo colectivo, primeramente, e individual; es decir, que reclama el derecho de todos al disfrute de un entorno seguro que favorezca el progreso personal, la cohesión social y la identidad cultural con igualitaria accesibilidad a las redes y circuitos de comunicación, información e intercambios. Esto va a depender, según el autor, de una propiedad esencial del espacio urbano: la centralidad y, por ende, ese derecho proclama la crisis inevitable de los centros basados en la segregación.

Este derecho, afirma Harvey (2008), no es simplemente el derecho a lo que ya está construido en la ciudad, sino el derecho a transformar la urbe en algo radicalmente distinto. Es entonces restaurar el sentido de ciudad a partir de la posibilidad del "buen vivir" para todos, y hacer del hábitat "el escenario de encuentro para la construcción de la vida colectiva”.

\section{El Programa de Autogestión para la Vivienda}

El Programa de Autogestión para la Vivienda, sancionado por la Ley 341 en el 2000, fue implementado y ejecutado por la Excomisión Municipal de la Vivienda -actual Instituto de la Vivienda de la Ciudad (IVC) $-^{11}$ a partir del año de su sanción hasta la actualidad en el ámbito de la CABA (Argentina).

Como consecuencia del proceso de descentralización del Fondo Nacional de Vivienda (Fonavi) ${ }^{12}$ y de la política habitacional en su conjunto -que se enmarcó en la Reforma Estatal de los noventa- ${ }^{13}$ se comenzaron

${ }^{11}$ Tras la autonomización de la CABA y la sanción de una Constitución, este organismo cambio de nombre: de Comisión Municipal de la Vivienda a Instituto de la Vivienda de la Ciudad, pero se mantuvieron varias en sus funciones y obligaciones.

${ }^{12}$ Se creó en 1972, mediante la Ley 19.929, pero su real funcionamiento e institucionalización se concretó cinco años después mediante la ley 21.581. Se concibió como un fondo continuado y circular (de retroalimentación en el tiempo) de financiamiento de vivienda para los sectores de bajos recursos (con capacidad de pago en relación al costo de amortización de la vivienda -sin llegar a los paupérrimos-), bajo un esquema de gestión altamente centralizado en la Secretaría de Desarrollo Urbano y Vivienda de la Nación (sDuv) como organismo de aplicación de la ley. Este organismo quedó facultado para establecer reglamentaciones, definir los programas a financiar (operatorias y normativas particulares), determinar las prioridades de inversión, sus respectivos cupos de aplicación por región, fijar la normativa para el manejo de fondos, así como los criterios generales de selección de los adjudicatarios (perfiles y sistema de puntajes). Pero en términos de implementación, los programas ejecutados desde el fondo quedaron descentralizados en los organismos provinciales de gobiernos (Cuenya, 1997).

${ }^{13}$ Ocurrida con la Reforma Estatal de los años noventa, a partir de la cual los recursos del Fonavi fueron totalmente descentralizados en su manejo hacia los tesoros provinciales, sin poder de fiscalización a nivel nacional sobre el destino de los mismos. El Estado Nacional transfirió a los institutos 
a dar, a nivel local, algunas modificaciones en las respuestas brindadas al déficit de vivienda. El gobierno de la ciudad implementó un nuevo modelo de política social habilitante de la participación social y procesos de producción social del hábitat (como se lo definió más arriba), en el que surgieron programas impulsados por organizaciones sociales vinculadas a la temática habitacional. El Programa de Autogestión para la Vivienda se inscribió en este registro, posibilitando en su desarrollo la participación social de los destinatarios de las viviendas que construye.

Este programa tiene por objetivo facilitar el acceso a la vivienda, de uso exclusivo y permanente, a hogares de escasos recursos en situación crítica habitacional de la ciudad. Otorga créditos con garantía hipotecaria a familias de escasos recursos para la compra de un terreno en la ciudad, la construcción de las viviendas y la contratación de un equipo técnico de profesionales que brinda asesoramiento. Sus beneficiarios son familias incorporadas a organizaciones colectivas verificables (como cooperativas, asociaciones civiles, mutuales, todas sin fines de lucro).

La Ley 341 fue concebida e impulsada por organizaciones sociales involucradas en la problemática del hábitat, como el Movimiento de Ocupantes e Inquilinos (MOI), la Mutual de Desalojados de La Boca, así como por el acompañamiento de organizaciones como el Comedor Los Pibes, los Delegados de la ExAu3 y otras organizaciones socioterritoriales que encontraron, a finales del siglo pasado, un canal de interlocución legítimo con legisladores de la ciudad que hicieron eco de sus reclamos.

Estos orígenes de la ley habilitaron -como innovación en materia de política social en Argentina- concebir a las organizaciones socioterritoriales como sujetos de crédito con garantía hipotecaria, uno de los principios que defendían éstas (aunque hasta el término de esta investigación no son las titulares finales de los inmuebles, ya que una vez finalizada la construcción de las viviendas la escrituración de éstas es de tipo individual, a través del régimen de propiedad horizontal) ${ }^{14}$ lo que significa para Rodríguez (2007: 110) que "procesos colectivos organizados y participativos tenderían a retraducirse en destinatarios individuales y pasivos".

Los créditos ofrecidos por el programa pueden ser utilizados para la financiación total o parcial de operatorias de compra o construcción de vivienda unifamiliar o multifamiliar, más la obra destinada a ampliación

de vivienda provinciales y a la CMV en la CABA la potestad de definir los requerimientos técnicos y financieros de los proyectos de vivienda, junto con el resto de las competencias que antes se reservaba la sDUV.

${ }^{14}$ Si bien en el 2010 se sancionó la Ley 1251/10, la cual promueve como opción la propiedad colectiva para organizaciones sociales, el jefe de gobierno porteńo, Mauricio Macri, la vetó por decreto. Nuevamente, en 2011 la Legislatura de la CABA votó la opción permanente (no como obligación) de la propiedad colectiva como alternativa posible para las cooperativas de la Ley 341. El MOI fue actor motor de ese proceso. 
o refacción o construcción nueva, más la contratación de un equipo técnico interdisciplinario de profesionales; o también puede ser utilizado para el financiamiento de obra destinada a la ampliación o refacción y el pago de honorarios a un equipo técnico de profesionales, si es que la organización social ya cuenta con el terreno.

En este sentido, una de las características sobresalientes del programa es que financia, además de la construcción de viviendas, la compra de terreno urbano en la ciudad para organizaciones sociales (configurando a éstas como actores destinatarios que desempeñan un rol activo ${ }^{15}$ en la elección de la localización), lo cual representa una innovación para los programas habitacionales de acceso a la vivienda social en Argentina.

Asimismo, el programa contempla la financiación del pago de honorarios a profesionales que conforman un equipo técnico interdisciplinario (ETI) integrado por las áreas técnica, social, contable y legal, ${ }^{16}$ para asesorar y acompañar a las organizaciones sociales a lo largo de todo el proceso constructivo, social y autogestivo del programa. Por lo tanto, la Excomisión Municipal de la Vivienda, hoy Instituto de la Vivienda de la Ciudad concedía a las organizaciones sociales un crédito hipotecario cuyo monto incluía el costo del terreno en la ubicación de la ciudad que las organizaciones eligieran, el de la construcción de las viviendas y de la contratación de un ETI.

Con lo cual, mediante la utilización de estos recursos estatales, las organizaciones sociales despliegan estrategias autogestivas de producción social del hábitat para la concreción de sus viviendas, ya sean en la búsqueda de los terrenos donde concretan sus proyectos, el control y la ejecución de la obra y el uso de las viviendas finalizadas, su cuidado y mantenimiento.

15 Diferenciamos actores con roles activos o pasivos de la política social como aquellos que tienen algún tipo de toma de decisión en el proceso de ejecución del programa del cual son destinatarios (Catenazzi y Chiara, 2009). Esta aclaración toma sentido en relación a la tradicional política habitacional desarrollada en la ciudad, en la que los destinatarios de los programas desempeńan un rol pasivo, pues no tienen ningún espacio de participación o toma de decisión sobre las viviendas que reciben.

${ }^{16}$ Los arquitectos del área técnica tenían a su cargo el asesoramiento de la cooperativa en cuestiones relativas al proyecto de vivienda, la búsqueda y compra del terreno, la elaboración de los planos, la gestión para la aprobación de planos; dirigían, coordinaban, supervisaban la obra (según la metodología de construcción seleccionada), entre otras tareas. Las acciones de los profesionales del área social consistían en la realización de actividades que estimularan la consolidación de los socios de la cooperativa como grupo, vía la realización de talleres de capacitación o actividades de discusión en materia de autogestión, cooperativismo y participación. También realizaban el proyecto social que exigía el PAV a las organizaciones para ser beneficiarias, el programa de trabajo para las distintas etapas de implementación de la operatoria y la realización de informes de seguimiento que debían ser presentados en el IVc. Los contadores asesoraban el seguimiento crediticio de las operatorias y control de gastos de la organización; mientras que los abogados asesoraban en todo lo relativo a la normativa y las cuestiones legales de la implementación del programa en cada organización social. 
Por otra parte, la norma estipula, en cuanto a la población destinataria del programa, que sus ingresos mensuales no superen la línea de pobreza y se encuentren en situación verificable de vulnerabilidad habitacional. También establece prioridad de acceso a aquellas personas en situaciones sociales de vulnerabilidad o en circunstancias sociales sensibles tales como: pérdida de vivienda a causa de siniestro, desalojo con sentencia judicial, estado de salud de uno de los integrantes del grupo familiar que requiera el cambio de las características de la vivienda, situaciones de violencia familiar comprobada, que habiten en inmuebles afectados por obra pública, familias enmarcadas en procesos de organización colectiva verificables, grupo familiar mono-parental con hijos menores de edad, ser exsoldados conscriptos de las Islas Malvinas del Atlántico Sur; entre otras.

En consecuencia, la norma establece una especial tutela para aquellos hogares que presentan alguna situación de vulnerabilidad habitacional, social o económica. Esta previsión legislativa se corresponde con lo dispuesto por el artículo 17 de la Constitución de la Ciudad Autónoma de Buenos Aires, ${ }^{17}$ la cual advierte sobre el deber del Estado local de desarrollar políticas sociales coordinadas para superar las condiciones de pobreza y exclusión.

Otro de los hitos progresistas del programa, que marcaron un punto de inflexión en la implementación de políticas orientadas a la provisión de vivienda social, tiene que ver con que la ley contempla la participación de los adjudicatarios en el diseño, implementación y evaluación del mismo -mediante reuniones periódicas con funcionarios del gobierno local y su participación en la Comisión de Control, Evaluación y Seguimiento (CCES)-, como en el diseño de sus viviendas y su ejecución constructiva, siendo controladores de la construcción de sus obras, ya sea mediante la elección del equipo técnico, la modalidad de construcción de sus viviendas - por prácticas de ayuda mutua, la contratación de cooperativas de trabajo o pequeńas empresas constructoras- y tomando todas las decisiones que incumben a la concreción de sus operatorias, en un ejercicio pleno de autonomía organizativa y de procesos de producción social del hábitat (como se definió arriba).

Ahora bien, no obstante el programa fue implementado y desarrollado intensamente en los primeros años (entre 2000 y 2006), posteriormente fue estancándose hasta su casi paralización por la gestión local actual que se limita a finalizar las obras ya iniciadas, coartando la posibilidad de incorporación de nuevas organizaciones sociales al programa.

\footnotetext{
${ }^{17}$ Artículo 17.- La Ciudad desarrolla políticas sociales coordinadas para superar las condiciones de pobreza y exclusión mediante recursos presupuestarios, técnicos y humanos. Asiste a las personas con necesidades básicas insatisfechas y promueve el acceso a los servicios públicos para los que tienen menores posibilidades.
} 
Estas restricciones expresaron los límites que el sistema político y la institucionalidad pública fijaron a las experiencias de autogestión del hábitat popular y producción social del hábitat en la ciudad.

\section{Los vaivenes del proceso de implementación del programa}

Cada gestión de gobierno que estuvo a cargo de la implementación del Programa de Autogestión para la Vivienda construyó distintas concepciones de lo que para ellos es la autogestión y un hábitat adecuado para los sectores de menores recursos. Con base en estas nociones, cada grupo de gestión construyó distintos vínculos con las organizaciones sociales que participan en el programa. Estas apropiaciones operaron en la práctica de implementación del pav a través de la utilización discrecional del presupuesto destinado al programa y la recurrente reorientación normativa de las resoluciones que norman el funcionamiento de la Ley 341.

Retomando conceptos de Oszlak y O’Donnell (1995) del modo en el que intervine cada gestión de gobierno, ya sea por acción u omisión de acciones, se puede inferir una determinada direccionalidad en la implementación del programa, un determinado cauce normativo que sostiene esa cierta direccionalidad que fue asumiendo el PAV y, consecuentemente, tuvo impactos en el curso de los procesos sociales hasta entonces desarrollados (los proyectos de autogestión). Cualquier cuestión (demanda o necesidad) socialmente problematizada atraviesa un ciclo de vida que se extiende desde este momento hasta su resolución, y en ese tránsito, diversos actores toman posición frente a la misma definiéndola, en función del impacto positivo o negativo que sufrieron del surgimiento y desarrollo de la cuestión.

Entre la multiplicidad de actores sociales que toman posicionamiento frente a una cuestión se encuentra el Estado mediante la ejecución, o no, de políticas públicas y la institucionalización, o no, de sus decisiones. No obstante, la toma de posición del Estado no tiene porque ser unívoca, homogénea ni permanente durante el desarrollo de la cuestión (Oszlak y O’Donnell, 1995), y más aún si atraviesa distintas gestiones de gobierno con orientaciones políticas e ideológicas diversas. El ciclo de vida del PAV se constituyó en un claro ejemplo de esta variabilidad en la posición del Estado ante una determinada cuestión social.

La primera gestión de gobierno que estuvo a cargo de la implementación del programa es la que aquí se denominó gestión Jozami. ${ }^{18}$ Antes de analizarla es importante decir que el grupo político que conformó este

\footnotetext{
${ }^{18}$ A cada gestión de gobierno se le atribuyó el nombre del presidente de la EXCMV-IVC del momento para su diferenciación empírica.
} 
equipo, junto con organizaciones sociales, fue el que en años previos canalizó el diseńo de la Ley 341 a la Legislatura de la CABA.

Ya con un pie en el poder ejecutivo de la ciudad, específicamente en la Excomisión Municipal de la Vivienda, este grupo introdujo la ley para su ejecución, produciendo un hito en cuanto a la modalidad de implementación de políticas públicas destinadas al hábitat. Pues la Ley 341 provocó una ruptura dentro de la excomisión en relación a la tradicional modalidad de ejecución de vivienda social, asociada a procesos licitatorios y grandes empresas constructoras como principales beneficiarias de la política. ${ }^{19}$

En esta etapa la normativa aún no estaba reglamentada, pero le adjudicaba a las organizaciones sociales una amplia autonomía en cuanto a su incidencia en la definición de las características que iba asumiendo el programa en su ejecución práctica. Esto modificó radicalmente la dinámica de funcionamiento diario de la excomisión y específicamente la relación entre los equipos de gobierno y las organizaciones sociales destinatarias, pues estas últimas se convirtieron en actores sociales activos de la política pública con amplio margen para la toma de decisiones.

Adicionalmente, la implementación de este programa significó la modificación de los procedimientos administrativos tradicionales de la excomisión, con sus resistencias consecuentes, pues sus empleados públicos ya no lidiaban con circuitos tradicionales de licitaciones o con empresas constructoras conocedoras de la burocracia estatal, sino con cooperativistas que desarrollaban de manera autónoma sus operatorias (algunos contratando pequeñas empresas constructoras, otras cooperativas de trabajo u otras realizando prácticas de autoconstrucción y ayuda mutua), pero ninguna de ellas trabajó con las empresas de gran envergadura con las que habitualmente negocia el IVC.

Ahora bien, la asignación presupuestaria correspondiente a la ley, en esta etapa, fue escasa, por un lado, por la falta de reglamentación para su instrumentación y, por otra parte, por la resistencia política al programa de los tradicionales sectores dedicados a la vivienda social. No obstante, la gestión en turno concretó reasignaciones presupuestarias para dar curso a la institucionalización del programa y comenzar con su ejecución a través de la compra de los primeros terrenos del programa; sin embargo, esta situación no fue sostenible en el tiempo, pues entre 2000 y 2002 los fondos destinados al pav fue en decrecimiento (de 6,320,986 a 1,847,134 pesos), aunque con altos niveles de ejecución (se alcanzó el cien por ciento)

Para profundizar en la historia de la política de vivienda social, leer capítulo III de Zapata 
expresados en compras de terrenos en la centralidad de la ciudad de Buenos Aires (como se verá más adelante).

No obstante las dificultades de implementación de estos primeros años, esta corta etapa sentó las bases para el ejercicio del derecho a organizarse por parte de los sectores de menores recursos en organizaciones sociales, para ser partícipes activos del diseño y primeras instancias de ejecución de una política pública que los tendría por adjudicatarios y para generar transformaciones en la anquilosada forma de funcionamiento de la excomisión.

Por su parte la gestión Selzer se caracterizó por imponerle un límite a la autonomía de las organizaciones sociales y a su capacidad de incidencia y participación en la ejecución del programa. Estas restricciones se expresaron a través de la sanción de la reglamentación de la Ley 341, la Ley 964 y el Acta de Directorio $\mathrm{N}^{\circ} 1647 / 03$, de manera poco participativa echando por tierra el proceso de mesas de debate para la reglamentación de ley que se venían desarrollando entre las organizaciones sociales y la gestión Jozami.

Esta reglamentación, poco consultada, inició un proceso de desnaturalización de la Ley 341, expresada en la escasa participación que desarrollaron las organizaciones sociales en el proceso de escritura y sanción de la misma, y en los pocos espacios de toma de decisión que se le reservó en la ejecución del PAV en el marco institucional. Esta falta de protagonismo de las organizaciones sociales se expresó en los pasillos de la excomisión, a partir de una sensación colectiva de retorno al comportamiento previo normal del organismo: "poca vinculación entre organizaciones sociales-empleados de la exCMv, canalización de la participación mediante talleres transmisores de capacidades autogestivas a las organizaciones y a los ETIs, lentificación y re-burocratización de los procedimientos administrativos de las operatorias, entre otras" (Zapata, 2013: 117).

Sin embargo, el impulso participativo de la gestión anterior de las organizaciones sociales se hizo sentir en esta etapa por la presión de 516 organizaciones que reclamaban su rol en el desarrollo del programa. En este sentido, las organizaciones sociales lograron por parte de la excomisión la adquisición de otra gran cantidad de terrenos en pleno centro de la ciudad y el inicio de obras de la mayoría de las operatorias que, a diciembre de 2012, se encontraban en construcción.

En esta etapa se alcanzó el punto máximo de desarrollo del programa en función de la cantidad de solicitudes presentadas y aceptadas por la excomisión (414 hasta 2005) y la cantidad de recursos humanos operando en el programa (25 técnicos). En términos presupuestarios, el programa, al contar ya con una reglamentación, comenzó a ser depositario de asignación presupuestaria e inició una etapa de asignaciones anuales 
ascendentes: el incremento presupuestario fue de $1283,5 \%$ en relación al año previo (se incrementó de casi dos millones a 24 millones de pesos).

Por lo tanto, los logros cuantitativos que tuvo el programa en esta etapa se mostró en contradicción con el límite que se le impuso desde la gestión. Entendemos este comportamiento contradictorio desde dos perspectivas distintas: una de carácter más estructural, pues el programa se implementó como consecuencia de la crisis habitacional que se desplegaba en la CABA hacia fines de la década de los noventa y principio de siglo y que afectaba directamente a la población asentada en inquilinatos, hoteles-pensión o casas tomadas; escenario que se encrudeció con la crisis del 2001 en Argentina, posicionando al PAV entre una de las únicas alternativas posibles de los sectores sociales de menores recursos (los más afectados de aquel momento por la crisis) para acceder a una vivienda digna.

No obstante, desde una perspectiva de carácter más sectorial, vinculado con el constante estado de movilización masiva de los sectores más vulnerables -que para ese entonces se encontraban fuertemente organizados en términos de lucha por sus derechos-, se ejerció presión a la gestión de gobierno en reclamo a sus derechos de vivienda social en el marco del PAV.

En el periodo de gobierno siguiente, la gestión Freidin, con una nueva definición del programa, sancionó, nuevamente, sin participación de las organizaciones sociales, otra modificación de carácter sustantivo a la normativa de aplicación y al Acta Directiva №2204/06. Mediante estas importantes modificaciones se transitó del concepto de autogestión (esgrimido por las organizaciones sociales tal como se mencionó arriba) al de co-gestión, entendida como la recuperación de responsabilidad del Estado en el programa planteando una modificación de la relación estadosociedad que se venía construyendo en el ámbito local y poniendo un nuevo límite al nivel de incidencia de la participación social de los adjudicatarios del programa (Zapata, 2013).

Entre las modificaciones que impulsó esta gestión, estipuló que los terrenos se compraran a nombre del IVC, los honorarios profesionales pasaron a ser abonados directamente por este organismo (por lo que dejaron de ser incorporados en el crédito a las organizaciones sociales) y el crédito se convirtió en una asistencia financiera sólo para la construcción de la obra. Estos cambios impactaron en el grado de autonomía que poseían las organizaciones sociales para decidir sobre su proyecto constructivo y social, para elegir a los profesionales con los que querían trabajar y ya, por ejemplo, no podían ingresar libremente a sus terrenos, pues ya no eran sus dueños (sólo podían hacerlo con la autorización del IVc).

Si bien se puso en funcionamiento la CCES como un medio de canalización de la participación social de las organizaciones sociales en el 
marco del programa, lentamente se fue produciendo un proceso de desarticulación y disolución de la misma, pues se convirtió en un espacio de disputa y controversias entre las organizaciones, abonado por la inacción estatal para revertir esta situación.

Esta voluntad política se transpoló al comportamiento del programa, pues los indicadores de avance del mismo comenzaron a mostrar signos de estancamiento: depresión de todos los indicadores de avances de las operatorias -como se verá más adelante-, fuerte recorte en la cantidad de empleados técnicos (sólo quedaron ocho) y se comenzó una etapa de flujo financiero discontinuo para las cooperativas que estaban con proyectos en construcción. Además, en esta fase se observó un retroceso significativo en materia presupuestaria, ya que al $2007,{ }^{20}$ la caída en el monto asignado al PAv fue muy brusca (de -47,6\%). Si bien en 2008 los indicadores se recuperaron, no alcanzaron los valores previos al 2006, año en el que el PAV representó sólo 13,9\% del presupuesto asignado al organismo, representando 52,797,021 pesos de un total de 379,681,093 pesos del IVC.

Esta tendencia se radicalizó con la llegada al gobierno local de un equipo de gestión con una orientación política definida como neoliberal y con una clara convicción de convertir a la CABA en una ciudad global ${ }^{21}$ al servicio del capital financiero. En este sentido, con la nueva gestión de gobierno a cargo del IVc, que aquí se nombró gestión Apelbaum, la paralización del PAV fue casi total y prácticamente no se habilitaron canales o espacios de articulación o participación con las organizaciones sociales del programa, las cuales instrumentaron numerosas medidas de protesta y resistencia y debieron ejecutar sus obras, en la medida que pudieron, en soledad. 22

El formato del pav y el grado de autonomía que tuvieron los sectores populares en la implementación del programa contradijo la definición neoliberal de la nueva gestión de gobierno, para la cual, el mercado cumple un rol activo y fundamental en la producción de vivienda social (y por ende los programas habitacionales que estimulan la participación de actores económicos en el sector) y no los sectores de menores recursos

\footnotetext{
${ }^{20}$ El presupuesto para el 2007 se debate en la Legislatura porteña hacia finales del ańo legislativo previo, a propuestas de los distintos organismos del poder ejecutivo.

${ }^{21}$ Para profundizar en las transformaciones que se plasmaron en la ciudad de Buenos Aires posterior al 2007, ver Rodríguez et al. (2012).

${ }^{22}$ Vale aclarar que los avances del pav a lo largo de todo el ciclo de vida del programa, dependieron de la capacidad propositiva y de presión del movimiento cooperativo y de la generación progresiva de vínculos de confianza con los actores estatales. Las decisiones tomadas en el marco del programa tuvieron una alta dependencia de la evaluación que los actores no políticos tuvieron acerca de la capacidad de articulación sociopolítica del movimiento cooperativo de la ciudad, pero también del potencial de movilización y ocupación del espacio público que los mismos desplegaron en el territorio.
} 
de la ciudad mediante procesos autogestivos que escapan a la lógica de la ganancia.

Esta concepción se expresó, nuevamente, en los indicadores de avances de las operatorias, ya que todos ellos se congelaron, se cerró el ingreso de nuevas organizaciones al programa, se suspendieron la mayoría de los inicios de obras previstos, se paralizaron la mayoría de las obras en construcción por falta de flujo financiero y se redujeron la cantidad de obras finalizadas. Además, se suspendieron todos los espacios de intercambio entre funcionarios políticos del programa y representantes de organizaciones sociales, asimismo, la cantidad de funcionarios y técnicos adscritos al PAV decreció aún más (a cuatro técnicos), los cuales también vieron mutiladas sus funciones (la mayoría de sus tareas ya no existen).

Ahora bien, en términos formales y legales, mediante la sanción del Acta Directorio N²350/08 se volvió atrás con los cambios introducidos por las actas citadas en las gestiones anteriores y recuperó, en la letra de la norma, el espíritu original del programa sancionado en la Ley 341, recuperando la concepción de autogestión esgrimida por las organizaciones sociales. Este reverso normativo sólo se entiende en la paralización que tenía por destino el programa durante esta gestión de gobierno, pues si bien, con esta modificación la gestión dio cause a un reclamo ya añejo de las organizaciones sociales, vinculado a recuperar sus niveles de participación, autonomía e incidencia autogestiva en el programa, se logró desarticular un reclamo bandera de las organizaciones; de tal forma que el funcionamiento real del mismo en esta etapa fue prácticamente nulo.

En este sentido, las ejecuciones presupuestarias del programa dieron cuenta de esta intencionalidad política, pues si bien los montos destinados al PAV se revirtieron, notando un incremento (por ejemplo, al 2009, el aumento fue de $112 \%$ ), las ejecuciones presupuestarias decrecieron registrándose en el 2009 sólo una ejecución de 49,3\% del presupuesto asignado y en 2010 se invirtió sólo 58,7\%, montos que para los entrevistados consultados sólo alcanzaba para cubrir los gastos administrativos del programa.

Su sucesor en el cargo, de igual signo político e ideológico, al frente de la gestión Abboud, desde finales del 2010, demostró una mayor afinidad y permeabilidad hacia las operatorias autogestivas del PAV. Esto se expresó en la habilitación y reconstrucción de algunos canales institucionalizados de participación social en el programa de las organizaciones con operatorias en obra o con proyectos aprobados para el inicio de obra.

Esto se instrumentó institucionalmente mediante el despliegue de mesas de trabajo multiactorales, conformadas por funcionarios, cooperativistas -independientes o participes en organizaciones sociales más amplias- y profesionales de equipos técnicos interdisciplinarios. Estas mesas 
de trabajo resultaron altamente participativas (aunque en muchas ocasiones acompañadas de metodologías disruptivas impulsadas por funcionarios públicos) que, con dificultades, permitió algunos lentos avances de las cooperativas que se encontraban en obra. Sin embargo, los resultados no llegaron a ser significativos ni se revirtió la tendencia macroestructural que vivió el programa en esos últimos años.

A pesar de esto, esta gestión de gobierno habilitó una ampliación presupuestaria al PAV para el 2011 que representó un aumento de $127 \%$ con respecto al año anterior (se incrementó de 68,190,000 a 154,964,684 pesos). Este aumento significativo sólo se entiende en la simpatía que encontró el presidente del IvC a este tipo de operatorias (respaldada en la posibilidad rápida de mostrar resultados de gestión con las obras en construcción avanzadas) y la recepción que encontró en la Legislatura porteña a su proyecto de gestión. Sin embargo, este presidente fue desplazado de su cargo por decisión del ejecutivo local hacia diciembre de 2011.

La última y actual gestión Basavilbaso, también de corte neoliberal, continuó con la línea de gestión del presidente Abboud, consolidando la relación con los cooperativistas. Se sostuvieron las mesas de trabajo con organizaciones sociales para repasar estados de avance de las obras en curso y comenzó a desarrollar una política de visita a las obras con los adjudicatarios de las operatorias como un modo de reentablar un vínculo de mayor cercanía. ${ }^{23}$

Esta política de acercamiento con las operatorias también representó un mayor impulso a las obras en curso y a algunas operatorias que ya contaban con terreno en la CABA para iniciar sus obras -tal como se verá en el gráfico 1 en el apartado siguiente-; pero no fue así con el resto de organizaciones que reclamaban la compra de terreno, pues ni levantó el cepo al ingreso de nuevas organizaciones al programa. Su política de gestión hacia el PAV se limitó a "finalizar lo que está comprometido" [Funcionario político actual del PAV-CABA, junio 2013] decía un alto funcionario del Ivc de la gestión actual.

Esta gestión de gobierno confeccionó un ranking de cooperativas para poder avanzar con aquellas que hayan tenido un mejor rendimiento a lo largo de la implementación del programa. Para esto se puso a disposición, además de los cuatro técnicos que quedaban de la gestión anterior, a cuatro asesores de la presidencia que se ocuparon específicamente del seguimiento de cada operatoria que se encuentra en curso.

${ }^{23}$ Y exponer a la opinión pública su capacidad de gestión. A diferencia de las gestiones anteriores, la actual desarrolla una política de comunicación y visibilidad de los procesos de gestión muy fuerte. Tras cada visita a organizaciones sociales se realiza por web y redes sociales una fuerte visibilización de los logros de la gestión. 
No obstante este impulso al programa, no se hizo palpable en la asignación presupuestaria para el 2013 (la cual fue sancionada por estímulo de esta gestión en la Legislatura porteña a fines de diciembre de 2012). Los créditos de la Ley 341 y el Programa de Autogestión para la Vivienda fueron anunciados como uno de los ejes de la gestión del IVC para el 2013, pero el presupuesto asignado se redujo en más de 40 millones de pesos si se compara con el del año anterior (con una asignación de 151,305,855 pesos). A pesar de este recorte, en este año, su ejecución fue de 77 por ciento.

Para el 2014 se preveía una mejora en la asignación sancionada (aumentó de 91,937,798 pesos en el 2013 a 112,700,512 pesos). El funcionario entrevistado expresó que desde su gestión prefieren priorizar el acotado presupuesto con que cuenta el programa en las obras que ya se encuentran en curso más que iniciar obras nuevas porque consideran que lograr que las obras finalicen es lo que generará un fondo propio para el programa. Restará por ver si en el curso de lo que resta de su gestión se logra una real activación del PAV.

En consecuencia, del análisis realizado del ciclo de vida del PAV a través de las diversas gestiones de gobierno se puede observar que las normas (leyes, reglamentaciones, actas reglamentarias) que dieron sustento legal al programa y las asignaciones presupuestarias del mismo, simularon una neutralidad política que en la implementación del paV claramente se puede afirmar que no existió, pues cada acta reglamentaria que modificó al programa, al igual que la ejecución presupuestaria, tradujo la interpretación y funcionalidad que cada gestión de gobierno quiso atribuirle al programa, ya sea por acción u omisión -según Oszlak- y partir de la lectura que cada gestión de gobierno hizo del concepto y la práctica de la autogestión de la vivienda social. En consecuencia, los avances y retrocesos de la producción autogestionaria del hábitat popular en la CABA han sido resultado de estas diversas definiciones institucionales de la política habitacional que hicieron desde las distintas gestiones del gobierno local.

\section{Características de las organizaciones sociales y el avance en sus proyectos autogestionarios}

Desde una mirada cualitativa, el perfil de los actores involucrados en el programa es una más de las particularidades del mismo. La mayoría de las organizaciones sociales que son adjudicatarias están conformadas por personas en situación de emergencia habitacional con escasas posibilidades de acceso a la vivienda a través del mercado formal-legal, provenientes de hoteles-pensión e inquilinatos y, en menor medida, villas de la ciudad. Los hitos de gestación de las organizaciones sociales que se 
conformaron en cooperativas de vivienda fueron diversos, algunas nacieron como resultado, o salida, de las asambleas barriales fundadas tras el estallido de la crisis de 2001 en Argentina, como la cooperativa Asamblea Primero de Mayo, otras, surgieron en el marco de parroquias y comedores barriales, entre ellas, las cooperativas Comedor Los Pibes y María del Rosario y, otras, como resultado de solidaridades entre profesionales o agentes por oficios tales como la cooperativa Construyéndonos y Crecer. Mientras que otras tantas se constituyeron como consecuencia de la convocatoria realizada por la excomisión, hoy instituto, a partir de la cual los vecinos en similar situación de precarización se organizaban y conformaban una cooperativa de vivienda para ingresar al programa, entre ellas, la cooperativa Emergencias y Uspallata (Acha y Verón, 2006).

Otras cooperativas nacieron a raíz de las experiencias de desalojos que sufrieron muchos de los habitantes de la zona sur de la ciudad de Buenos Aires hacia fines de la década de los noventa como la cooperativa El Palomar y Caminito, otros eran adjudicatarios de la operatoria enmarada en la Resolución No525/9724 que fue desactivada hacia finales de la década, pasando automáticamente a estar amparados por la Ley 341 y el programa de autogestión como es el caso de la cooperativa La Ribera y Asociación Civil Copitos; otras cooperativas surgieron como alternativa del Programa de Recuperación de la Traza de ExAu3 $3^{25}$ como la cooperativa Argentina Puede y Sembrar Conciencia.

Además, se conformaron cooperativas de vivienda a razón de compartir una nacionalidad, como es el caso de Puka Llajta y Santa Rosa de Lima donde predominaron socios con nacionalidad peruana o cooperativa 28 de Junio, donde prevalecieron socios bolivianos. La mayoría de los grupos familiares que conformaban cooperativas de viviendas e ingresaban al programa compartían una misma trayectoria habitacional: haber transitado por situaciones de villas de emergencia o asentamientos precarios o algunas modalidades de hábitat precario del tipo de hoteles, pensiones, inquilinatos o casas tomadas.

Al mismo tiempo, dentro del programa existe un abanico de cooperativas de viviendas que se conformaron en el marco de organizaciones

\footnotetext{
${ }^{24}$ La Resolución n525/97 estuvo destinada a la financiación directa de la demanda mediante créditos individuales o mancomunados dando respuesta a un proceso de movilización de sectores locales amenazados por desalojos iniciados por el proceso de renovación urbana en el barrio de La Boca.

${ }^{25}$ El Programa de Recuperación de la Traza de ExAu3 tiene por objetivo reconstruir el tejido urbano y social del área correspondiente a la franja de inmuebles expropiados por el último gobierno militar (1976-1983) con el fin de construir la autopista AU3 que nunca se concretó; brindar vivienda económica a los beneficiarios; iniciar el proceso de solución habitacional definitiva, y garantizar la estabilidad habitacional de los beneficiarios durante el proceso que demande el desarrollo del mismo; atender en forma integrada y coordinada, entre los diversos organismos de gobierno, los problemas sociales de los beneficiarios.
} 
sociales más amplias, muchas de ellas fundadoras del programa, y que además desempeñan un rol en el escenario político de la CABA. Este es el caso de cooperativas que integran el Movimiento de Ocupantes e Inquilinos (MOI), ${ }^{26}$ el Movimiento Territorial de Liberación (MTL), ${ }^{27}$ la Federación de Cooperativas del Polo Obrero, ${ }^{28}$ el Movimiento por Vivienda y Trabajo (мVT), ${ }^{29}$ entre otras.

Por otro lado, ya desde un abordaje cuantitativo del programa, con base en datos procesados por el rvc y la Comisión de la Vivienda de la Legislatura Porteña, a diciembre de 2013, el PAV contaba con un total de 519 organizaciones sociales inscritas, es decir, 10,101 familias organizadas. De este universo de cooperativas de vivienda, mayoritariamente, y asociaciones civiles, en menor medida, 110 de ellas (que involucran a 2,484 familias) habían comprado terreno en la CABA, restando todavía 409 organizaciones sociales $\left(78,8 \%\right.$ del total) que aún no lograron adquirir terreno. ${ }^{30}$

En el grupo de las 110 cooperativas de vivienda y asociaciones civiles que adquirieron terreno, existen diversas situaciones que se pueden subagrupar (de modo analítico) según el nivel de avance de los proyectos de autogestión: 46 organizaciones sociales que contaban con terreno ya adquirido con fondos públicos del programa pero que aún no lograron iniciar sus obras (que representan $41,8 \%$ de las organizaciones del programa); ${ }^{31} 41$ organizaciones que se encontraban con sus obras actualmente en construcción, 903 familias (37,3\%), 23 organizaciones (21\%) ya finalizaron sus obras y 736 familias ya están habitando esas viviendas y cuatro cooperativas ya escrituraron de manera individual sus viviendas ${ }^{32}$ (74 familias ya están devolviendo el crédito prestado).

${ }^{26}$ Organización socioterritorial de carácter sectorial, nacida a finales de los años ochenta a partir de experiencias de organización de ocupaciones de edificios. Desarrolla proyectos de vivienda y hábitat popular mediante procesos colectivos, democráticos y participativos, políticamente está ligado a la Central de Trabajadores Argentina (СTA).

${ }^{27}$ Agrupación piquetera que forma parte del Bloque Piquetero Nacional, una de las organizaciones de trabajadores ocupados y desocupados más radicalizadas; políticamente ligada al Partido Comunista (PC) y a la CTA.

${ }^{28}$ Agrupación piquetera con filiación política al Partido Obrero (PO).

${ }^{29}$ Organización territorial conformada en el marco de reclamo por el correcto funcionamiento de la Ley $n^{\circ} 341$. Se encuentra conformada con organizaciones sociales beneficiarias de este programa que coincidan con la idea que a partir de la solidaridad pueden lograr sus objetivos dentro del programa. No cuentan con filiación partidaria o política explícitamente definida.

${ }^{30}$ Los motivos que se encuentran para explicar esta falta de solución radican, por un lado, en el alza constante de los precios del suelo en la CABA, que prácticamente consume el total del monto adquirido por las organizaciones y, por otro, las distintas trabas administrativas y políticas del curso de implementación del programa (que se analizan en este artículo).

${ }^{31}$ Dieciséis de estas organizaciones ya se encuentran listas en términos administrativos, a la espera de la llegada de los fondos.

${ }^{32}$ Es importante señalar también que existe seis cooperativas de viviendas de la organización La Lechería que cuentan con un alto grado de avance en sus obras (por encima de $90 \%$ ), y al ser intervenida por la justicia por irregularidad en el manejo de los fondos, sus adjudicatarios decidieron 


\section{Cuadro 1 \\ Estado de avance de operatorias del PAV CABA, diciembre de 2013}

\begin{tabular}{lcc}
\hline \multicolumn{1}{c}{ Estado de obras } & Proyectos & Cantidad de viviendas \\
\hline Obras terminadas* & 23 & 736 \\
Obras en ejecución & 41 & 903 \\
Obras a iniciarse & 46 & 842 \\
Total & 110 & 2.484 \\
Viviendas finalizadas escrituradas & 4 & 74 \\
Cooperativas inscriptas & 519 & 10.101 \\
\hline Fuente: Elaboración propia con base en datos aportados por el IVC y Legislatura porteña.
\end{tabular}

Con base en el análisis de las 110 cooperativas que actualmente cuentan con terreno en la CABA a razón del PAV, en el gráfico 1 se discrimina por años, distintos indicadores que permiten analizar la evolución del programa a lo largo del tiempo. En este sentido, se verifica que todos los indicadores de avance crecen hasta el periodo 2004-2006, donde se registran los picos más altos y coinciden con los años de mayor estímulo al programa por las gestiones de gobierno en turno, y a partir de allí todos los indicadores de desarrollo decaen (cuando se produjo un cambio de concepción del paV desde gestiones de gobierno de corte neoliberal). En el último periodo se registra una leve mejoría en la cantidad de obras finalizada y viviendas escrituradas (como ya se vio, la recuperación del programa en estos indicadores hablan de un intención de gestión de terminar las obras que están en curso a fin de demostrar capacidad de gestión).

Analizando la cantidad de solicitudes de ingreso al PAv, lo que se verifica es que hasta el periodo 2004-2006 este indicador aumentó de manera sostenida, llegando a un pico en el 2005 de 147 solicitudes presentadas. A partir de ese ańo, la cantidad de solicitudes de ingreso comenzó a decrecer, llegando a no aceptar inscritos nuevos al programa a partir del 2008 (aunque hubo numerosas solicitudes).

Esta etapa de restricción del PAV a nuevas inscripciones coincidió con el momento en el que los entrevistados (tanto adjudicatarios como funcionarios) ubicaron el cierre del programa o, en palabras de un funcionario del IVC, concordó con la definición política de poner un coto o límite al programa y establecer un universo cerrado de organizaciones sujetas al mismo.

ocupar las viviendas de hecho. En esta situación se encuentran unas 93 familias que hoy están habitando viviendas en el barrio de Mataderos. 


\section{Gráfico 1 \\ Evolución de indicadores de avance del PAV por periodos 2000-2013}

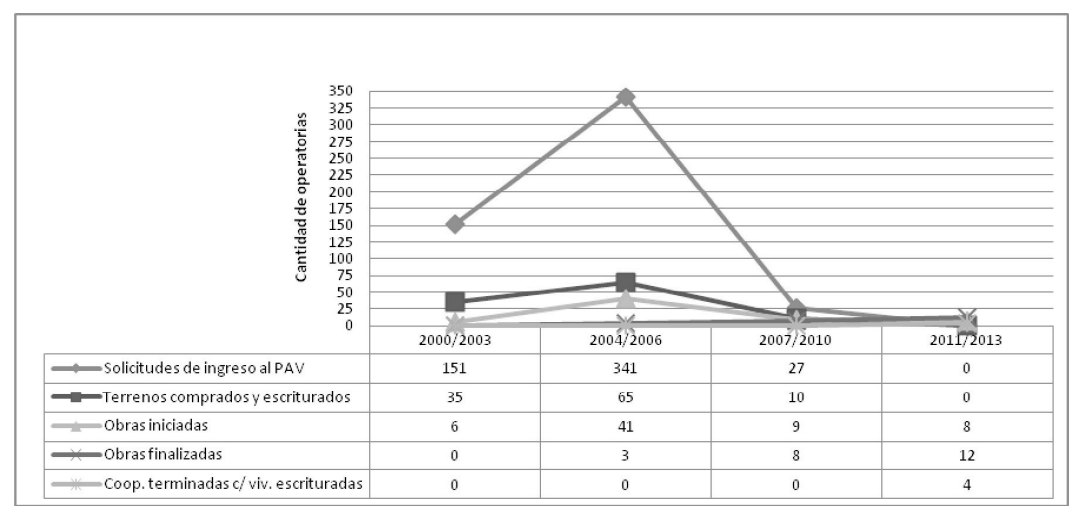

Fuente: Elaboración propia con base en los datos aportados por el Ivc y Legislatura porteña.

No obstante este límite, el alud de solicitudes por parte de las organizaciones sociales dio cuenta de la valorización que las personas con necesidades habitacionales realizaron de sus operatorias a la hora de buscar una solución para su problemática de vivienda; al tiempo que también expuso el limitado grado de cobertura que pudo dar el Estado a la demanda real de créditos para autogestión (de las 519 solicitudes que hubo, la Excomisión Municipal de la Vivienda-Instituto de Vivienda de la Ciudad sólo dio respuesta a 21,2\% de las organizaciones solicitantes).

En cuanto a los indicadores de inmuebles comprados, hasta el periodo que finaliza en 2006, los valores también fueron en aumento, registrándose cierta constancia en la compra de terrenos entre 2002-2003 y, principalmente, de 2004 a 2006 se restringe el accionar del programa.

Con la llegada, en 2007, al Ivc de la gestión Apelbaum, de definición claramente neoliberal, se acentuó el descenso de esta curva con una caída significativa. En el periodo de 2004 a 2006 se compraron la mayor cantidad de inmuebles en la ciudad, invirtiendo 7,073,680 pesos, sólo en el 2006. Sin embargo, a partir del 2008 ya no se compraron terrenos en la ciudad en el marco de este programa.

Del grupo de organizaciones con terreno, 96 de ellas escrituraron sus inmuebles a nombre de sus entidades y 14 (algunos de los comprados en 2006 y todas las adquiridas en 2007, bajo la gestión de gobierno a cargo del arquitecto Freidín) se escrituraron a nombre del Ivc. A diciembre de 2012, estas 14 organizaciones reclamaban al IVc la transferencia de la escrituración de estos terrenos a las organizaciones sociales ya que ellos entendían esta práctica como un límite al ejercicio de su autonomía en 
el proceso de autogestión de sus obras (por ejemplo, para poder ingresar a sus terrenos debían pedir autorización previa al IVc). Como ya se vio, este límite en la escrituración de los terrenos estuvo asociado a un cambio de concepción de la "autogestión de organizaciones social" por "co-gestión de organizaciones sociales y estado" de una nueva gestión de gobierno que estuvo a cargo del programa.

Por otra parte, en cuanto al indicador de inicio de obra, se verificó que a diciembre de 2013 se encontraban con un avance promedio de construcción de al menos 45\%. En las primeras etapas de implementación del programa, hasta el 2006, los inicios de obra fueron constantes hasta alcanzar un pico en este año de 15 obras. En 2010 no se llegaron a registrar inicios de obra, pero a partir del 2011 se consignó una mejoría, pero a cantidades notoriamente menores que en la etapa inicial del programa. Esta recuperación del indicador de inicios de obras se corresponde con la nueva gestión de gobierno de corte neoliberal que tiene por objetivo obtener resultados, por lo que se propuso finalizar las obras empezadas y encauzar aquellos proyectos de organizaciones que tienen terreno en la CABA, pero que aún no han iniciado obra.

En cuanto a las obras que están finalizadas y que sus familias adjudicatarias ya están habitando las viviendas, este indicador es el que se muestra más constante de todos a lo largo del tiempo, pero también es el que se recupera de mejor manera hacia los últimos años, alcanzando los picos en el 2012 y 2013. Desde el 2004 hasta la actualidad siempre se han registrado al menos una obra finalizada, alcanzando un pico en el año 2008 con tres operatorias finalizadas e inauguradas. Entre 2006 y 2007 se inauguraron dos cooperativas resolviéndoles el problema habitacional a 354 familias (aunque la mayor cantidad de viviendas inauguradas se verificó en el 2006 a razón de la inauguración de la Cooperativa Emetele, un complejo de 326 viviendas, construido por la cooperativa de trabajo del MTL). Pero con base en los nuevos objetivos de gestión sólo en los dos últimos años se finalizaron 10 operatorias de las 23 finalizadas hasta la actualidad, expresando en sobremanera la nueva decisión política del programa (mostrar resultados y capacidad de gestión).

Por último, en cuanto al indice de escrituración, de las cooperativas de vivienda ya finalizadas y habitadas, cuatro cooperativas (incluyendo a 31 viviendas de las 326 viviendas de la Cooperativa Emetele) ya escrituraron sus viviendas de manera individual y ya se encuentran devolviendo el crédito otorgado. 


\section{Las soluciones habitacionales del PAV: ¿posibilidad de acceso al derecho a una vivienda digna y la ciudad para los sectores de menores ingresos?}

A lo largo de los años - a pesar de las trabas institucionales de implementación- el Programa de Autogestión para la Vivienda se fue configurando en un campo de disputa de los sectores populares por el derecho a una vivienda digna y a la ciudad. Aún con limitantes externos, como la compleja institucionalización del programa (explicada más arriba) y limitaciones internas de las propias organizaciones sociales, el PAV presentó rasgos novedosos y superadores en relación al resto de los programas habitacionales vigentes y promovidos por las últimas gestiones en la ciudad.

Las 736 viviendas finalizadas que hoy existen en la CABA en el marco de 23 proyectos cooperativos construidos por el PAV resultaron ser un estímulo para el resto de las organizaciones sociales que diariamente sostienen la lucha por el derecho a la ciudad y a una vivienda digna y un hábitat adecuado en el país. De la misma manera, estas operatorias se conformaron en un ejemplo de los resultados constructivos y sociales que implica la implementación de una política habitacional autogestionaria que involucra a sus adjudicatarios como actores activos del programa y no como meros receptores de una llave.

Los pequeños complejos habitacionales que se inauguraron dejaron una marca en el parque habitacional de vivienda social de la ciudad, ya sea por sus estilos constructivos (la mayoría de ellos no expresan una ruptura con el patrimonio urbano y arquitectónico de la trama urbana en la que se enclavaron), como por sus consecuentes aspectos sociales (en términos de una integración socio-urbana más sencilla de sus adjudicatarios a la trama urbana en la que se insertaron los complejos). Es importante notar que los proyectos constructivos de cada operatoria se desarrollaron de la mano de proyectos de construcción social de los cooperativistas que luego fueron convivientes y vecinos de los complejos habitacionales, transformando significativamente la subjetividad de cada una de las personas que participó en estos procesos, ya sea en términos de aprendizaje, de aspectos vinculados al desarrollo, de las obras y su relación con el Estado, como en términos de formación y construcción de sujetos sociales activos conscientes de sus derechos.

En este sentido, a pesar de los límites que se le impuso el proceso autogestivo en la ciudad desde la estatidad pública y el condicionado impacto cuantitativo del PAV (en un escenario de emergencia habitacional), todos los actores sociales intervinientes en el programa (tanto a adjudicatarios de las organizaciones, como a integrantes de los ETI y a funcio- 
narios) valoran las potencialidades de una política con estas características. El actual presidente del IVC decía:

\begin{abstract}
Para nosotros es un modelo que, mejorándolo, nos gusta mucho la Ley 341, hay que mejorar muchas cosas, que ninguno devolvía su crédito, que ninguno había escriturado. Por otra parte, son créditos que tienen un $4 \%$ de tasa a 30 años, con una inflación del $30 \%$ es demasiado subsidio, hay algunas cooperativas que podrían pagar más tasas, con el ánimo de poder dar más créditos [...] nosotros queremos que sea una ley que funcione para muchas cooperativas. Pero por sobre todo a nosotros nos gusta porque dentro de lo que es las soluciones habitaciones, ofrece el metro cuadrado más barato que conseguimos dentro del IVC, porque la autogestión lo que consigue es que las cooperativas construyen muy barato. Entonces, es un modelo que si lo podemos mejorar es un modelo muy bueno [Presidente actual del IVC -CABA, julio 2013].
\end{abstract}

En este sentido, según cooperativistas entrevistados, una de las potencialidades del programa es la posibilidad que brinda de diseñar proyectos en función del tamaño y características de las familias que luego vivirán en las viviendas, obteniendo edificios de escalas más chicas, con niveles de adaptación a las necesidades de los adjudicatarios muy altos (por ejemplo, teniendo en cuenta la composición de las familias por cantidad, sexo y edad, previendo constructivamente impedimentos físicos de algún integrante, preferencias de diseño, posibilidades de crecimiento interno de las viviendas, entre otros).

Además, existió un tratamiento diferencial con los materiales constructivos en relación con los tradicionales proyectos de vivienda social, pues la mayoría de los proyectos realizaron recuperación de fachadas o fachadas que remiten a la historia los barrios en los que se insertan, utilizaron materiales distintos al hormigón (como vistas de ladrillo descubierto), etc. Estas mejoras, en términos de "calidad de obra" tal como lo llaman los arquitectos de los ETI, repercuten en una valorización positiva de la dimensión estética (que usualmente no se dio en las viviendas de tipo social). Los complejos habitacionales construidos por el PAV provocaron una ruptura con la usual ecuación vivienda social-baja calidad demostrando en los 23 complejos habitacionales finalizados que esta ecuación puede ser revertida.

Ahora bien, el sentido común diría que este tratamiento especial de las obras repercute en un mayor costo final de las operatorias, construyendo edificios más caros que los edificados por las tradicionales grandes empresas constructoras habituadas a levantar complejos habitacionales. Sin embargo, las cooperativas, al tener un crédito con un monto fijo para la construcción de sus viviendas, en virtud de la autogestión de sus proyectos, deben conseguir precio en los materiales de construcción para poder cubrir con el crédito el mayor costo posible. Por ende, las coopera- 
tivas salen al mercado a buscar y negociar precios convenientes (en los casos más organizados hasta han realizado acopio de materiales en post de abaratar costos) logrando construir a un costo menor por metro cuadrado que los complejos llave en mano construidos por el estado-mercado.

Figuras 1, 2 y 3
Fachada de cooperativa El Molino (MOI), Asociación civil Sembrar Conciencia y cooperativa Uspallata CABA, 2013
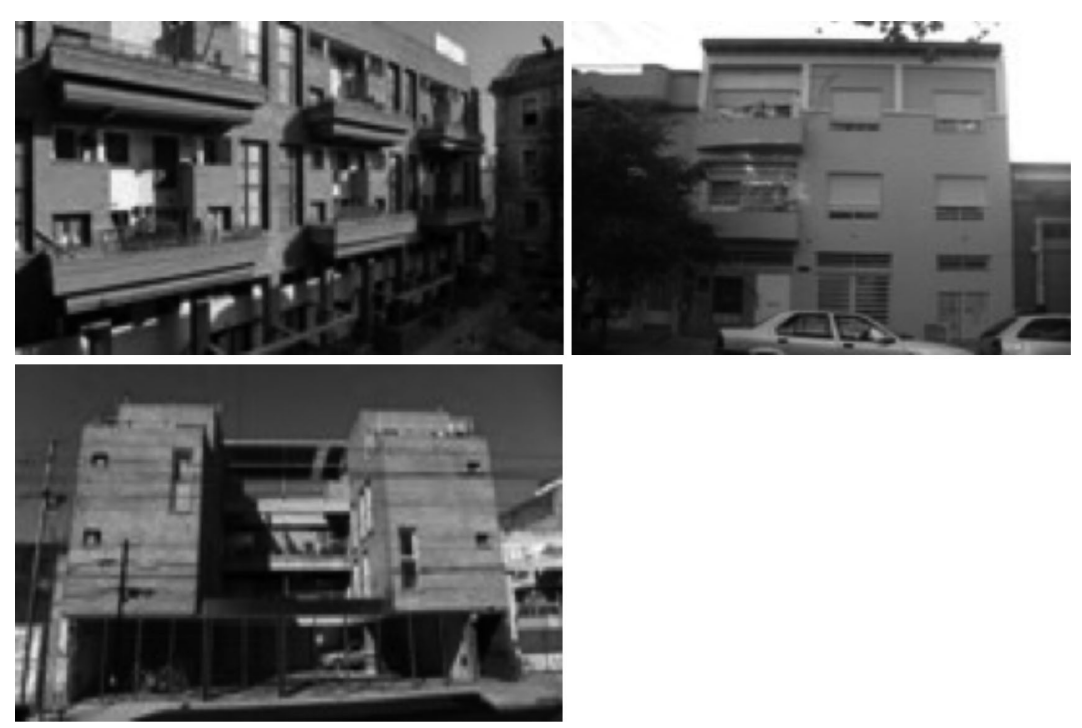

Fuente: Fotografías tomadas por Kaya Lazarini y Cecilia Zapata.

El actual presidente del Ivc comentó: "Nosotros calculamos que aproximadamente por cooperativas están construyendo entre 600 y 700 dólares el metro cuadrado, y hoy en la ciudad se construye aproximadamente a 1000 dólares el metro cuadrado, nos conviene trabajar con cooperativas" [Presidente actual del IVC-CABA, julio, 2013].

En consecuencia, este tipo de programas autogestivos generó un proceso de eficientización del gasto de los recursos del Estado, logrando resultados de mejor calidad y mayor adaptabilidad a las necesidades habitacionales de los adjudicatarios:

... como el recurso que tienen es un financiamiento finito [...] la guita es como si fuese de ellos, entonces peleaban hasta el último centavo. De esta manera podes eficientizar la gestión del Estado a través de la autogestión, pero esto precisa aceitar muchos mecanismos, el instituto no estaba ni aún hoy está preparado para eso, el instituto tenía cuando nosotros llegamos cerca de 1,000 personas acostumbradas 
a la políticas habitacionales llave en mano, y no entienden que la autogestión es totalmente otra lógica" [Expresidente del IVC-CABA, septiembre, 2010].

Ahora bien, este proceso de construcción de los edificios (en muchos casos mediante procesos de diseño participativos de la vivienda) se desarrolló en forma paralela a un proceso de construcción social de apropiación de la vivienda y de pertenencia por parte de los adjudicatarios del programa, expresada en la capacidad de decidir en el tipo de vivienda que quieren vivir:

También los cooperativistas podían decidir sobre las terminaciones de obra, por ejemplo. Se hacían talleres para trabajar eso entre todos... una vez armamos un taller para trabajar las dimensiones de los departamentos que estuvo excelente. El arquitecto trajo dibujado un departamento en una escala trabajable y el dibujo de los muebles, y los cooperativistas tenían que ir llenando o decorando sus casas. Fue muy bueno porque vivenciaron sus propias casas y además se dieron cuenta de las dimensiones que tendría cada departamento [Socióloga, ETI de Cooperativa Independencia-САBA; agosto, 2010].

En este sentido, la participación social se dio como un proceso de apropiación del ejercicio del derecho a una vivienda digna y a un hábitat adecuado. Pero también, el PaV permitió el desarrollo de un proceso de apropiación de suelo urbano de calidad por parte de los sectores de menores recursos de la ciudad (en un marco actual de profunda disputa por el espacio urbano por parte de todos los actores sociales) y de las oportunidades comunitarias, sociales y urbanas ligadas a la localización.

La escala pequeña de los complejos habitacionales (salvo excepciones, el promedio de familias por cooperativas es de 20) admitió excelentes localizaciones para operatorias del PAV, la mayoría de ellas en plena centralidad urbana, rompiendo con la lógica de segmentación social y segregación urbana de las políticas habitacionales tradicionales de vivienda social. Como se puede ver en el mapa a continuación, la localización de las operatorias muestra una concentración importante de familias de bajos recursos en barrios consolidados y con muy buena accesibilidad a la zona céntrica de la ciudad, revelando las ventajas que habilitó el PAV en términos de ejercicio del derecho a la ciudad (Zapata, 2013).

Además, la escala de las operatorias del PAV, en su mayoría pequeñas, no produce una ruptura con la trama urbana existente en la que se inser$\tan$ las operatorias. De las 2,484 viviendas de los 110 proyectos con terreno en la ciudad, el tamaño promedio de los conjuntos es de poco más de veinte unidades por proyecto, por lo que el impacto urbanístico de los mismos es bajo, y favoreciendo la renovación del tejido degradado de la ciudad (en detrimento de los grandes complejos habitacionales construi- 
dos en zonas vacías o de casas bajas del sur de la ciudad irrumpiendo el tejido urbano).

Estas pequeñas escalas de los complejos favorecen, además, la integración de sus adjudicatarios a la trama urbana en el que se insertan, habilitan un aprovechamiento igualitario de las ventajas comunitarias y urbanas que posibilita una buena localización territorial. La construcción a gran escala va de la mano de la disponibilidad de suelo urbano existente, lo que hizo inevitable que los grandes complejos habitacionales se ubicaran en la zona sudoeste de la ciudad, por la existencia de grandes terrenos libres; creando en la zona sur de la ciudad grandes islotes de segmentación social y segregación urbana. El PAV introdujo un cuestionamiento a este patrón tradicional de política habitacional que históricamente respondió más a los intereses y a la rentabilidad de las empresas constructoras involucradas que a criterios urbanísticos o sociales de necesidad habitacional.

Además, el pAV demostró cierta capacidad de crear organización entre los sectores que no tienen la capacidad de resolver su problema habitacional vía el mercado inmobiliario: "Como herramienta fue espectacular, es un cambio total de visión, que la gente se apropie realmente de su vivienda y, además, es crear organización, más allá de todo el contexto y todo lo demás, ahí lo que se creó fue organización" [Funcionario de la Excomisión Municipal de Vivienda-CABA; septiembre, 2010].

La posibilidad de organización colectiva que abrió el programa como modalidades de resistencia a las definiciones de política habitacional creó un precedente sin igual a nivel local: "Lo bueno de este programa es que formó organizaciones en la ciudad. Y vos ves que la gente lo pelea, que quizás individualmente no lo harían ni lo lograrán. Y hoy hay un circuito de organizaciones de vivienda dando vuelta en la ciudad. Y el cambio es abismal en relación a los créditos individuales que daba el IVC antes" [Socióloga, ETI de Cooperativa Independencia-CABA; agosto, 2010].

Esta valoración positiva que se realiza de la autogestión como modelo de construcción social y de vivienda, en varias entrevistas, fue comparada con la modalidad de respuesta habitacional que tradicionalmente ofrece el IVC a los sectores de menores recursos a través de programas llave en mano:

Hay un teórico colombiano ${ }^{33}$ que crítica todo esto porque dice que la autogestión es cargar sobre la espalda de las personas más vulnerables la construcción de sus propias casas; cuando otros defendían la autogestión porque la gente se apropia mucho más, las operatorias son completamente diferentes a la entrega llave en mano de la vivienda. Y yo que vengo trabajando en vivienda desde hace mucho

\footnotetext{
${ }^{33}$ La entrevistada hacía referencia a Emilio Pradilla, un urbanista colombiano que criticó fuertemente la auto-construcción como modalidad de acceso a la vivienda para sectores de menores recursos.
} 


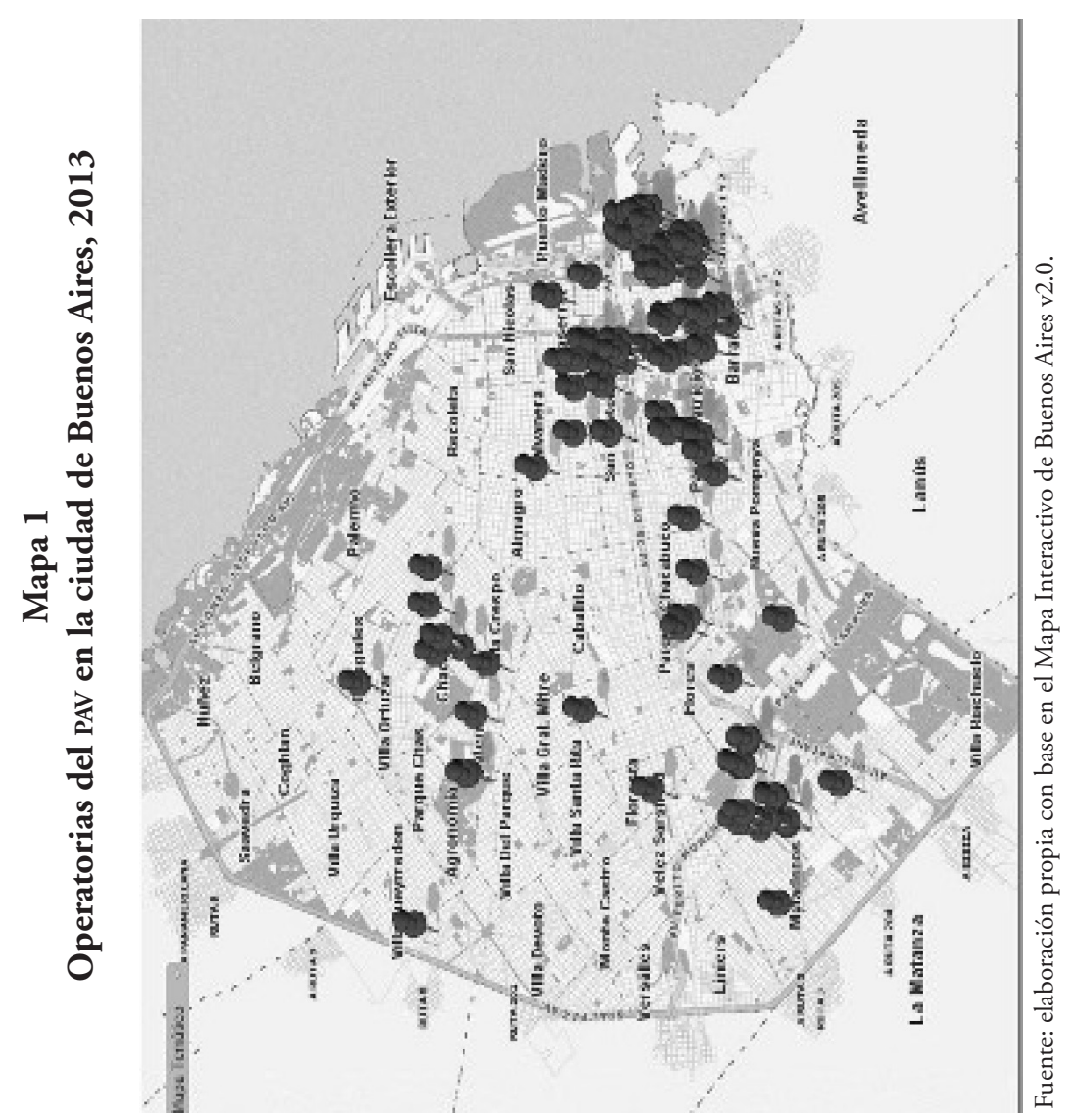


tiempo, y conozco todos los vicios que produce la llave en mano, que la gente no se apropia, y el descuido, y los espacios comunes que terminan siendo espacios de nadie, o peor, espacio tomados, todo esto muy devaluado. Por ahí la idea de una participación mucho más importante, una apropiación mucho más importante, y pensado la vivienda como un proceso y no como un producto, era un cambio radical [Funcionaria de la Excomisión de Vivienda-CABA; octubre, 2010].

En consecuencia, a continuación se resumen las ventajas que el Programa de Autogestión para la Vivienda le brinda a los adjudicatarios:

a) Proyectos constructivos con superficies adecuadas a la composición familiar de los adjudicatarios.

b) Tratamiento especial de materiales constructivos y valorización de la dimensión estética con altas repercusiones en los niveles de calidad de las construcciones.

c) Eficientización del gasto de los recursos públicos y estatales.

d) Mayor sentido de apropiación y pertenencia de los adjudicatarios de las viviendas.

e) Apropiación por parte de sectores de escasos recursos (históricamente segregados de la ciudad) de suelo urbano de excelente localización, en zonas consolidadas de la ciudad de Bs. As.

f) Mayor integración de los adjudicatarios del programa al entramado urbanístico en el que se insertaron.

g) Habilitó procesos de organización colectiva.

A pesar de los distintos vaivenes del proceso de institucionalización del Programa de Autogestión para la Vivienda, éste marcó un hito en la modalidad de abordaje de los problemas habitacionales e implicó un avance sustantivo en la lucha por el derecho a una vivienda digna y un hábitat adecuado y a la ciudad por parte de aquellos sectores de menores recursos de la Ciudad de Buenos Aires.

\section{Conclusiones}

Si bien es cierto que el proceso autogestionario de vivienda de la CABA canalizado institucionalmente a través del pAv fue complejo, con marchas y contramarchas políticas que impactaron en su implementación, las 736 viviendas sociales finalizadas a diciembre de 2013 se convirtieron en la vidriera de una opción distintas de política pública posibilitadora del acceso a una vivienda digna y a la ciudad.

Cada gestión de gobierno que estuvo al frente de la Excomisión Municipal de Vivienda-Instituto de Vivienda de la Ciudad adaptó a la Ley 341 a su particular concepción de lo que para ellos era la autogestión, 

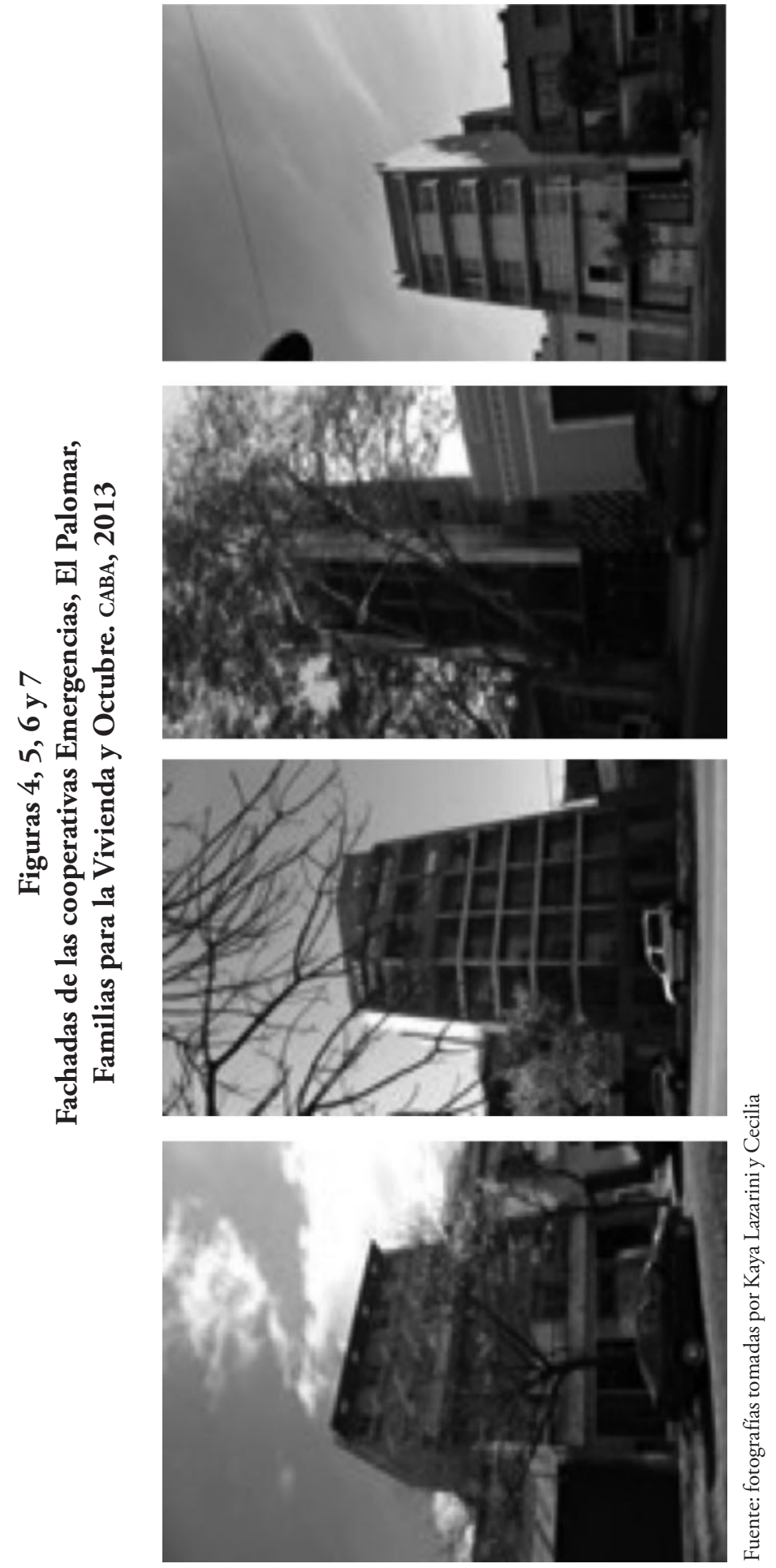
dejando de lado a las organizaciones sociales que fueron sus principales originadores. En función de esta lectura que realizó cada gestión, hicieron un particular uso de los recursos estatales para su implementación, ya sea aumentando o recortando el presupuesto destinado al programa y los recursos humanos abocados al mismo: habilitando, cerrando o morigerando espacios o canales de participación social, impulsando o frenando los procesos de ejecución administrativos del programa.

No obstante estos límites y limitantes impuestos por la institucionalidad pública, Thomasz (2008) remarcaba que la participación de las organizaciones sociales en el proceso de edificación de las viviendas, así como la autonomía que gozaron para llevarlo a cabo se expresó en la libertad que tuvieron las organizaciones de elegir a las personas con quienes deseaban asociarse, a fin de solicitar el crédito, así como la forma asociativa que desearon darse (cooperativa u otra) y los profesionales del ETI con los que deseaban trabajar.

Se agrega aquí, además, que los cooperativistas eligieron libremente la localización de los terrenos o inmuebles a comprar, la estética de la obra a realizar y la modalidad constructiva con la que desarrollarían sus proyectos (ya sea mediante la contratación de una empresa constructora para la realización de toda la obra o la práctica de ayuda mutua para algunas tareas o autoconstrucción). Estas tomas de decisiones por parte de los adjudicatarios dio cuenta de la construcción de derecho a vivienda, al hábitat y a la ciudad (en términos de acceso a la centralidad urbana y a sus condiciones de oportunidad), poniendo un freno a la lógica de segmentación social y segregación urbana de las políticas habitacionales tradicionales para los sectores de menores recursos.

En virtud de su carácter autogestionario, el proceso de edificación de las viviendas no fue concebido y conducido por la exCMV-IVC (como suele ser en las operatorias de llave en mano) sino por las organizaciones sociales, aunque con el financiamiento y la supervisión de dicho organismo. Además, por primera vez en un programa habitacional se incorporó a las organizaciones sociales como sujetos de crédito. En este sentido, el programa fue diseñado desde una perspectiva integral del problema habitacional, puesto que además de los recursos económicos y técnicos de seguimiento y monitoreo propios del IVC, a cargo de la CCES, se previó la participación activa de los adjudicatarios en todo el proceso (administración de recursos y obligaciones, libre elección de las empresas constructoras o cooperativas de trabajo y los equipos técnicos interdisciplinarios, los ETIs, diseńo participativo de las obras, entre otras), en un proceso verdaderamente innovador en la ciudad.

Las distintas medidas de lucha implementadas por los cooperativistas para mantener en vigencia al PAV y lograr las partidas presupuestarias para 
ejecutar sus obras, la construcción de las viviendas y la toma de decisiones que vino aparejada con la participación en un programa autogestivo como el PAV generó formas de solidaridad y capacidades organizativas que no se obtienen cuando a una persona se le otorga una vivienda ya construida. La nueva subjetividad y conciencia social lograda por las personas que forman parte de estos procesos estuvo indisolublemente ligada a la experiencia de autogestión, cooperación, participación y convivencia que implican estas experiencias.

Construir caminos alternativos de carácter asociativo y colectivo diferentes del modelo económico y social, hoy imperante en la sociedad, es un reto, pero de ninguna manera algo imposible (Cafardo, 2003). Las distintas experiencias cooperativistas que se generaron en el marco de la Ley 341 y el PAV demostraron que esto es possible, y que la salida a los problemas urgentes de las personas debe sustentarse en lazos de solidaridad, organización e igualdad.

\section{Fuentes consultadas}

Acha Patricia y Natalia Verón (2006), "El cooperativismo en la ley 314 de autogestión de vivienda en la ciudad de Buenos Aires", ponencia presentada en el IV Encuentro de Investigadores Latinoamericanos en Cooperativismo, 15 y 16 de septiembre, Rosario.

Apaolaza Ricardo (2009), “Autogestión de la vivienda popular y producción del espacio urbano en la ciudad de Buenos Aires -El caso del Complejo Monteagudo-", tesis de grado, Universidad de Buenos Aires, Buenos Aires.

Brenner, Neil y Theodore, Nik (2002), Espacios del neoliberalismo: la reestructuración urbana en América del norte y Europa occidental, Blackwell Publishers, Londres.

Borbón Alejandro Florián (2003), "De habitantes a ciudadanos: algunas reflexiones sobre el derecho a un lugar para vivir", Mundo Urbano, núm. 21, Universidad Nacional de Quilmes, Buenos Aires, pp. 1-5.

Cafardo Analía (2003), "Fucvam, una aproximación teórica a la principal experiencia cooperativa de viviendas en Uruguay", Cuaderno de trabajo núm. 11, Centro Cultural de la Cooperación, Buenos Aires.

Catenazzi Andrea y Magdalena Chiara (2009), "La participación en la gestión: alcances y límites en su institucionalización”, en Magda- 
lena Chiara y Mercedes M. Di Virgilio, Gestión de la politica social, Prometeo Libros, Buenos Aires, pp. 201-214.

Cuenya Beatriz (1997), "Descentralización y política de vivienda en Argentina”, en Beatriz Cuenya y Ana Falú, Reestructuración del Estado y politica de vivienda en Argentina, Centro de Estudios Avanzados de la Universidad de Texas, Austin.

De Mattos Carlos A. (2002), "Transformaciones de las ciudades latinoamericanas. ¿Impactos de la globalización?”, Revista EURE, 28 (85), Pontificia Universidad Católica de Chile, Chile, pp. 6-11.

Harvey David (2007), Breve historia del neoliberalismo, Editorial Akal, Madrid.

Harvey David (2008), "El derecho a la ciudad", The New Left-Review, núm. 53, Madrid, pp. 23-40.

Lefebvre Henri (1968), El derecho a la ciudad, Ediciones Península, Barcelona.

Oszlak Oscar (1991), Merecer la ciudad. Los pobres y el derecho al espacio urbano, Estudios Cedes-Humanitas, Buenos Aires.

Oszlak Oscar y Guillermo O’Donnell (1995), "Estado y políticas estatales en América Latina: hacia una estrategia de investigación", Redes, 2 (4), Universidad Nacional de Quilmes, Buenos Aires, pp. 99-128.

Rodríguez M. Carla (2007), Políticas del hábitat, desigualdad y segregación socio-espacial en el Área Metropolitana de Buenos Aires, Área de Estudios Urbanos, Instituto de Investigaciones Gino Germani, Buenos Aires.

Rodríguez M. Carla, Soledad Arqueros Mejica, Mariana Gómez Schettini, Florencia Rodríguez y M. Cecilia Zapata (2012), "Ciudad, políticas públicas y hábitat popular en la era $\mathrm{PRO}$ : continuidades y cambios en contextos de renovación”, en Herzer Hilda (comp.), Barrios al Sur: renovación y pobreza en la ciudad de Buenos Aires, El café de las ciudades, Buenos Aires, pp. 39-72. 
Sassen Sakia (1997), "Las ciudades en la economía global”, Simposio La ciudad latinoamericana y del Caribe en el nuevo siglo, Banco Interamericano para el Desarrollo, 13-15 de marzo, Barcelona.

Sassen Sakia (2002), Global Networks, Linked Cities, Routledge, Nueva York.

Thomasz Ana Gretel (2008), "Historia y etnografía de una normativa polémica: la Ley 341 y el Programa de Autogestión para la Vivienda", Cuadernos de la Antropología Social, núm. 28, Universidad de Buenos Aires, Buenos Aires, pp. 127-149.

Zapata M. Cecilia (2013), El programa de autogestión para la vivienda: el ciclo de vida de una politica habitacional habilitante a la participación social y del derecho al hábitat y a la ciudad, Instituto de Investigaciones Gino Germani, Universidad de Buenos Aires, Buenos Aires.

Zapata M. Cecilia (2014), “De los programas 'llave en mano' a los programas por autogestión. Un análisis de la provisión de vivienda social en la Ciudad de Buenos Aires desde la perspectiva del derecho a la vivienda y a la ciudad", tesis para obtener el grado de doctor, Universidad de Buenos Aires, Buenos Aires.

Recibido: 9 de octubre de 2013. Reenviado: 18 de junio de 2014. Aceptado: 12 de agosto de 2014.

Ma. Cecilia Zapata. Doctoranda en ciencias sociales por la Facultad de Ciencias Sociales, magíster en administración pública por la Facultad de Económicas, de la Universidad de Buenos Aires (UBA). Profesora de la asignatura de Sociología de dicha facultad. Actualmente es investigadora becaria del Consejo Nacional de Investigaciones Científicas y Técnicas (Conicet) con sede en el Área de Estudios Urbanos (AEU) del Instituto de Investigaciones "Gino Germani” de la Facultad de Sociales de la UBA. En el AEU es integrante de varios proyectos de investigación UвAут у se especializa en el estudio de políticas urbanas, en especificidad las habitacionales, a nivel local y en diversas modalidades de acceso a la vivienda social por parte de los sectores de menores ingresos. Además, es docente de la misma casa de estudios de la asignatura Introducción al conocimiento de 
la sociedad y el estado, cátedra A. Brailovsky, del Ciclo Básico Común. Entre sus últimas publicaciones destacan: "Respuesta local a un déficit habitacional local”, Revista Astrolabio. Nueva Época, núm. 8, Universidad Nacional de Córdoba-Conicet, Córdoba, pp. 290-322 (2012); en coautoría: "Ciudad, políticas públicas y hábitat popular en la era PRO: continuidades y cambios en contextos de renovación”, en Herzer H. (comp.), Barrios al Sur: renovación y pobreza en la ciudad de Buenos Aires, El café de las ciudades, Buenos Aires, pp. 39-72 (2012); "Acceso al suelo de calidad para sectores populares. Balance de la Ley No 341/964 y el Programa de Autogestión de la Vivienda”, en Di Virgilio, Herzer, Merlinsky y Rodríguez (comps.), La cuestión urbana interrogada. Transformaciones urbanas, ambientales y políticas públicas en Argentina, El café de las ciudades, Buenos Aires, pp. 109-130 (2011). 